\title{
Techno-economic performances of future concentrating solar power plants in Australia
}

Alberto Boretti (10 ${ }^{1 凶} \&$ Stefania Castelletto ${ }^{2}$

The prediction of the techno-economic performances of future concentrated solar power (CSP) solar tower (ST) with thermal energy storage (TES) plants is challenging. Nevertheless, this information is fundamental to energy policymakers. This work aims to fill the knowledge gap regarding estimations of costs, amount, and quality of electricity produced by these plants over their lifetime. Every estimate should be based on real-world data of actual costs incurred to build and maintain constructed plants, and their actual electricity production, sampled with high frequency, to be reliable. Here we discuss as the available information is insufficient. There has been so far very limited transparency on the real cost and performance of CSP plants built and operated worldwide, and in the very few cases where data has been made public, for example, Crescent Dunes in the United States, costs have been much higher than expected, while annual average capacity factors have been much less. Important statistical parameters such as the standard deviation of the capacity factor with high-frequency sampling have never been provided. We conclude as the techno-economic performances of these plants are therefore unpredictable with accuracy until a significant number of plants will be built and operated, their costs and operating parameters will be shared, and their delivered techno-economic performances will be compared to the modeled values, finally permitting validation of the techno-economic analysis tools.

\footnotetext{
${ }^{1}$ Deanship of Research, Prince Mohammad Bin Fahd University, Al Khobar 34754, Saudi Arabia. ${ }^{2}$ School of Engineering, Royal Melbourne Institute of Technology (RMIT) University, 3083 Bundoora, Melbourne, VIC, Australia. 凶email: a.a.boretti@gmail.com
} 


\section{Introduction}

oncentrated solar energy in Australia has been the subject of few works (Baig et al., 2015; Clifton and Boruff, 2010;

Dawson and Schlyter, 2012; Peterseim et al., 2014; Ghadi et al., 2019; Middelhoff et al., 2022; Narimani et al., 2016), with however practically no plant built and operated so far. Worth mentioning there is only a small 9 MW Fresnel section added to a coal-fired power plant to pre-heat the feedwater, which does not qualify as a concentrated solar power (CSP) plant. Hybrid plants concentrated solar energy plus biomass are becoming popular in the literature (Middelhoff et al., 2022), while hybrid plants concentrated solar energy plus coal were more favored until recently in the academic works (Ghadi et al., 2019), despite it is acknowledged also locally as the dispatchability of CSP plants with thermal energy storage (TES) makes this opportunity extremely attractive (Narimani et al., 2016). The last few years have seen a dramatic increment of installed capacity of wind and solar facilities, with these latter facilities in the case of Australia limited to large and roof-top photovoltaic (PV) only. No facility has been built yet or is being built, featuring concentrated solar power (CSP). This anomaly needs an explanation, that is not available in the current literature. Also uncovered in the current literature are the potentials of the CSP technology in Australia, despite the debacles suffered so far.

As shown in Fig. 1, data from the Department of the Environment and Energy (2019), in the last fiscal year of the statistic (2017-2018), the contribution of the variable and unpredictable wind and variable, unpredictable and intermittent solar PV was 5.74 and $3.80 \%$, with worth to mention also a reliable and dispatchable hydro contribution of $6.07 \%$. Since the end of the 1980 s, when the renewable energy contribution was about $10 \%$ hydro, and $0 \%$ solar photovoltaic and wind, there has been therefore a dramatic increment of wind and solar, but a reduction of hydro. Biomass was $0.5 \%$ at the end of the 1980 s and it is $1.5 \%$ now. Geothermal was, and it is, negligible. The growth of wind and solar is partially balanced by the reduction of hydro. This reduction is simply the result of the wholesale pricing of electricity in Australia.

The National Electricity Market (NEM) grid, covering only part of South Australia, Tasmania, Victoria, Australian Capital Territory, New South Wales, and Queensland, is presently fed with a growing amount of wind and solar PV energy, that is balanced by the combustion of fossil fuels, and the hydroelectric production, to cover the demand.

The NEM grids stretch for about $5000 \mathrm{~km}$ from Port Douglas, tropical north Queensland, to Port Lincoln, South Australia, also serving Tasmania across the Bass Strait. As the NEM market is a wholesale market where "retailers" buy and "generators" sell electricity, with the peak wholesale spot prices about $14 \mathrm{AU}$

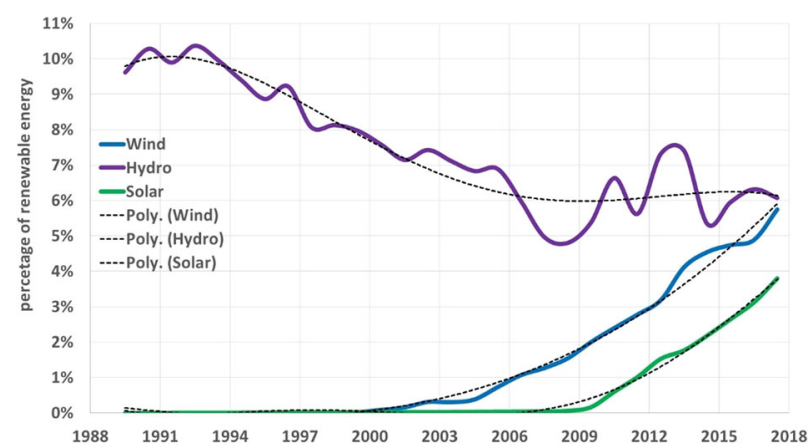

Fig. 1 Contributions of hydro, wind, and solar to the NEM grid. Data from the Australian Government Department of the Environment and Energy (2019).
$\$ / \mathrm{kWh}$ compared to an average of about $10 \mathrm{c}$ AU $\$ / \mathrm{kWh}$, hydro generation is run for maximum profit and not maximum production.

Figure 2 (from Aneroid Energy, 2019) presents a sample grid average production of electricity of wind and large solar PV over a sample month, July 2019. Being the wind energy production proportional to the wind energy resource, individual wind farms have capacity factors $\varepsilon$, the ratio of generating power to nominal capacity, variable from zero to $100 \%$, with averages of about $30-35 \%$ over a year. In terms of grid average $\varepsilon$, despite the exceptionally long grid, grid averages $\varepsilon$ may go down to even below $5 \%$ or above $60 \%$. Even worse variability is provided by solar PV, with everyday production going to zero during the night, and up to a maximum during the daytime that differs dayby-day and season-by-season, reaching sometimes $100 \%$. Variability is still substantial also at the grid average level.

Owing to this irregularity, wind or solar facilities of total power $\mathrm{X}$ need balancing facilities, either conventional combustion fuels or hydro-gravity, of about the same total power $X$. This is the reason why the cost of electricity for consumers has increased from about $10 \mathrm{AU} \$ \mathrm{c} / \mathrm{kWh}$ up to 2007 when there was no wind nor solar, to the already $25 \mathrm{AU} \$ \mathrm{c} / \mathrm{kWh}$ of 2013 (Parkinson, 2013), up to the present above $40 \mathrm{AU} \$ \mathrm{c} / \mathrm{kWh}$. To support a larger uptake of wind and solar, energy storage is needed, and this will introduce additional costs, apart from technological challenges.

Pumped hydroelectric energy storage (PHES) is the easiest way to supply electric energy storage (Rehman et al., 2015).
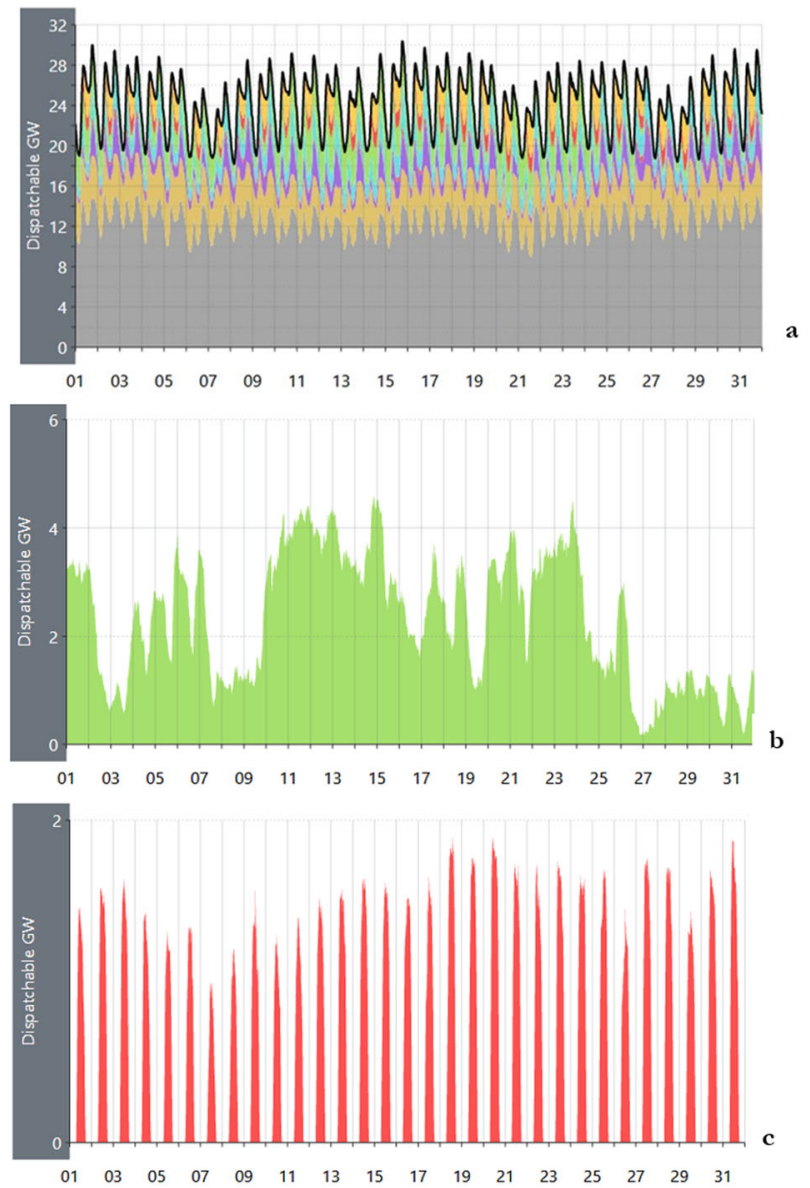

Fig. 2 Energy production by the source in the NEM grid during July 2019. a Totals. b Wind. c Solar photovoltaic facility. Images reproduced with permission from Aneroid Energy (2019). 
Unfortunately, PHES has round-trip efficiencies of 70 to $80 \%$, less than the $95 \%$ round-trip efficiency of Li-ion batteries. While traditional hydro-gravity plants are being upgraded to PHES by adding a pumping facility, and the largest energy storage facility of Australia, the 1800 MW Tumut 3, is PHES, as these plants were already providing on-demand production of electricity, their support is limited.

The further expansion of PHES in Australia should progress along the coast, where cliffs may provide the required head. However, salt-water PHES is everything but an established technology. A single pilot plant has been built, briefly operated, and then dismantled all over the world.

Added to PHES, battery energy storage (BES) is the other promising technology, with the largest Lithium-ion battery, the 150 MW/194MWh MW Hornsdale facility, located nearby the Hornsdale wind energy facilities to help to balance the output. The latest $50 \mathrm{MW} / 64 \mathrm{MWh}$ phase 2 of 2019 had a cost of 71 mAU\$ (50 m US\$). Coupled for example to solar PV of daily cyclic variability, if we take daily cycles 30 to $80 \%$ state-of-charge, over a 15 years' life span, this is an additional cost of storing/ releasing the energy of US $\$ 28 \mathrm{c} / \mathrm{kWh}$. If the life span increases to 30 years, that is fairly optimistic, this is still US\$ $14 \mathrm{c} / \mathrm{kWh}$. Thus, even if we produce electricity with solar PV at the optimistic cost of $4 \mathrm{c} / \mathrm{kWh}$, the cost for having solar PV electricity all day will be $(4+4+14) / 2=11$ to $(4+4+28) / 2=18 \mathrm{c} / \mathrm{kWh}$ (day and night are on average $12 \mathrm{~h}$ a day).

Thus, there is the opportunity to benefit from the construction of CSP ST with TES in Australia, as this is the only solar technology that permits some sort of dispatchability without the need for external energy storage. CSP with TES has the advantage of dispatchability without external energy storage. Hence, these facilities may deliver an output much closer to power on-demand or constant power than wind and traditional solar PV can do.

CSP ST, according to Kuravi et al. (2013), Liu et al. (2016), and IRENA (2012) are expected to quickly take over CSP PT, because of the alleged advantages of higher efficiency in converting sun energy to electricity. CSP needs significant direct normal radiation (DNI), and electricity production in concentrated solar power falls dramatically with cloud coverage. CSP is not competitive in cost with $\mathrm{PV}$, which also suffers much less cloud coverage.

The advantage of CSP is the opportunity to store energy in the molten-salt TES, as shown in Yang and Garimella (2010), Herrmann et al. (2004). TES allows in principle to fully decouple electricity production from the availability of solar energy. This opportunity is developed more, the larger is the number of hours of the TES design. CSP, as a dispatchable form of solar energy, has a significant added value vs. PV.

The work aims to explain why Australia has an expanding capacity of wind and solar PV power plants but has not built yet a single CSP plant, and why this situation is going to change shortly aiming at a renewable energy-only grid.

\section{Methods}

Summary of recent CSP projects in Australia and the rest of the world, with estimated levelised cost of electricity compared to wind and solar PV. Inclusion of energy storage for dispatchability in the costs comparison.

\section{Results}

The first CSP plant supposed to be built in Australia was the Aurora power plant, featuring about the same of the technology of Crescent Dunes in the United States, CSP ST with molten-salt TES. This technology generates solar power concentrating sunlight onto a small area (Boerema et al., 2013; Müller-Steinhagen and Trieb, 2004). The solar field is a large array of many dual-axis heliostats concentrating sunlight onto the central receiver atop the tower. The concentrated light warms up the molten salt to the hot tank. Steam is then produced in a heat exchanger between the molten-salt hot and cold tank. The steam expands in a turbine to generate electricity (Law et al., 2014; Law et al., 2016). The condenser is air-cooled and sometimes evaporative or hybrid.

The signature of the power purchased agreement (PPA) for Aurora was wrongly assumed as proof that fully dispatchable solar energy was possible at $6 \mathrm{c}$ US $\$ / \mathrm{kWh}$ in Australia. This claim was neglecting the additional source of revenues from the largescale-generation-certificates (LGCs), and the no-interest loan provided to the developer, and even more than that, the extremely poor performance of the already built Crescent Dunes plant featuring the same design in the United States, delivering about $1 / 4$ of the expected electricity subjected to many failures.

From a very subjective view of the PPA for Aurora, the $150 \mathrm{MW}$ rated power, $135 \mathrm{MW}$ under normal operating conditions, the plant was claimed to have an alleged cost of only AU\$ 650 million (US\$ 457 million), and the ability to deliver $495 \mathrm{GWh}$ of fully dispatchable electricity annually over 20 years. The subjective claim that fully dispatchable solar electricity could, therefore, be produced at US\$ 0.061 with the specific technology circulated in the press (smh.com.au, 2018; reneweconomy.com.au, 2018; ABC News, 2017), as well as the peer review (Pitz-Paal, 2017; Lilliestam et al., 2017; Lilliestam and Pitz-Paal, 2018; Feldman and Margolis, 2018). Murphy et al. (2019) moved even further, to forecast costs of US $\$ 0.05$ per kWh by 2030 of this specific technology based on the PPA for Aurora.

The actual costs were larger. The LGCs were valued at around AU\$ 80/MWh, which was already more than double the cost. A low-interest loan of 110 million AU\$ was also provided to the developer. Then, from the consumers' perspective, there were to factor indirect costs of the larger share of unreliable electricity production in a state, South Australia, where peak power prices were already up to AU\$ $14,000 / \mathrm{MWh}$ after the closure of the state coal-fired power plants.

The single plant of the same technology as Aurora built in the world by the same developer, Crescent Dunes, Tonopah, Nevada, USA, of $110 \mathrm{MW}$ capacity net, and $10 \mathrm{~h}$ of molten-salt TES, had a cost of 975 million US\$ in 2015 values, corresponding to 1046 million US\$ at 2019 values. However, while the planned electricity generation was $500,000 \mathrm{MWh} /$ year $(\varepsilon=51.89 \%)$, the actual electricity produced in the best year up to the time the PPA was signed was only $127,308 \mathrm{MWh} /$ year $(\varepsilon=13.21 \%)$.

As discussed in Boretti (2019a), to expect roughly six times better electricity production per $\$$ invested (slightly less than three times better electricity production at slightly less than half the cost) of what was built and operated, in a worse site for what concerns the direct normal irradiance (DNI), $2382 \mathrm{kWh} / \mathrm{m}^{2} / \mathrm{yr}$. vs. $2671 \mathrm{kWh} / \mathrm{m}^{2} / \mathrm{yr}$., and with slightly less promising plant details, $2 \mathrm{~h}$ shorter TES, and dry, rather than the hybrid cooling condenser, was contemptibly optimistic. No investor, therefore, decided to risk on this project, which was canceled, ABC News (2019).

Unfortunately, the failure of the Aurora project, as well as the premature closure of the Crescent Dunes plant in the United States, and the cancellation of the other similar projects in the world by the same developer, has dramatically reduced the chances that CSP could grow in Australia as well as the rest of the world.

The failure is due to the surpassed design and the use of substandard components to pursue the impossible goal to compete price-wise with solar PV without accounting for the dispatchability. If dispatchability is not valued, then CSP with TES cannot compete with solar PV. While trying to make CSP ST with 
TES for $6 \mathrm{c} / \mathrm{kWh}$ in 2019 was impossible, just a few c/kWh more for a better design could have provided a cost-effective solution (again, when BES is factored, costs of solar PV are 11 to $18 \mathrm{c} /$ kWh).

Forecasting of cost and production of plants CSP with TES has been done so far (NREL, 2018) adopting surveys by expert panels not based on real-world plant utility-scale built and operational. NREL proposes "consensus trends" for $\varepsilon$ and Levelized costs of electricity (LCOE) that are not based on any reliable statistic. They only consider CSP ST with TES and neglect the much more reliable and widespread PT technology. The cost and performance prediction by IRENA (2012), the starting point for the NREL predictions, was similarly made without any plant utilityscale (>100 MW) built. No real-world experience was included in the projections.

Remarkable, after the Crescent Dunes plant was finally built and operated featuring the reference technology, but delivering worse performances despite the higher costs, the forecasted cost and production were revised by NREL in the wrong direction by taking into consideration instead the power purchase agreement (PPA) signed for Aurora (Boretti, 2019a).

Analyses of the performance of utility-scale solar thermal power projects, in which actual performance and cost are compared to the predicted performance and the projected cost in which PT technology is compared to ST technology have been recently added to the literature (Boretti, 2018a, 2018b; Boretti et al., 2018). Projections of costs and performances by NREL have not yet reflected these real-world experiences.

Apart from Australia, which provides real-world production data of every power station with 3 min sampling frequency, and the United States, which provides data every month, the information about the real-world operation of renewable energy facilities is mostly unavailable. Unfortunately, Australia never had a CSP plant.

The number of CSP plants operational worldwide is limited, as shown in Table S.1 in the Supplementary. Most of these plants have been completed only recently, for none of these plants the information of electricity production with a high sampling rate is available. Only for the stations within the US, there is enough information with monthly data available since completion, but no high-frequency sampling.

Regarding the power stations of Morocco, there is no data on electricity production, apart from data of the year 2017 leaked by a student doing an internship in Noor 1 .

Similarly missing are the data of the electricity production from the plants of China, South Africa, and India.

For the power stations in Spain, sometimes the figures for annual electricity production have been circulated. However, the data are not public domain as it is in the United States.

Regarding the power station in the UAE, it was reported (Sills and Daya, 2010), that because of substantial atmospheric dust, solar radiation received by Shams' solar collectors was less than expected and more collectors would be required. Information about other difficulties operating in the harsh environment of the Gulf is not provided. Since 2013, no electricity production has been published. The figure presented in Table S.1 for electricity production from the listed source is unclear if predicted or delivered, and it is of uncertain origin. From Table S.1, it appears that only the PT technologies can be considered mature, with TES or without TES. The number of plants built and operated so far with also data available permits the definition of a small, but still, significant statistical sample, to be used for forecasting. Opposite, the information about the ST technologies is less, as there is in practice only one example to consider without TES (Ivanpah), plus only one example with TES (Crescent Dunes). From Table S.1, the only two plants $>100 \mathrm{MW}$ featuring ST presently operational in the world with data available are the $110 \mathrm{MW}$ net Crescent Dunes, of 2019 actualized cost of 9509 US $\$ / \mathrm{kW}$, and the 377 MW net Ivanpah Solar Electric Generating System (ISEGS), Ivanpah, California, USA, of 2019 actualized cost 6260 US\$/kW. ISEGS has a distinctive design, boosting production of the ST without TES burning natural gas to ramp up (and support) production.

Completed in 2015, the 110 MW CSP ST with molten-salt TES of Crescent Dunes, of 2019 actualized cost of 9509 US $\$ / \mathrm{kW}$, has delivered annual $\varepsilon$ of $13.03 \%$ in $2016,4.42 \%$ in 2017 , and $21.49 \%$ in 2018 . It is $5.39 \%$ in 2019 after the plant was shut down in April, still better than the 2017 result. The planned $\varepsilon$ of Crescent Dunes was much better than the delivered, $51.89 \%$.

Better $\varepsilon$ are delivered by recent CSP PT installations, solar only with no TES, such as the $2014250 \mathrm{MW}$ net Genesis, of 2019 actualized cost of $5360 \mathrm{US} \$ / \mathrm{kW}$ or the $2014250 \mathrm{MW}$ net Mojave, of 2019 actualized cost of 6880 US $\$ / \mathrm{kW}$. Solar only with TES plants, such as the $2013250 \mathrm{MW}$ net Solana, of 2019 actualized cost $8720 \mathrm{US} \$ / \mathrm{kW}$, are also working better.

Completed in 2014, Genesis has delivered annual $\varepsilon$ of $28.51 \%$ in $2016,28.61 \%$ in $2017,28.46 \%$ in 2018 , and $28.14 \%$ in 2019 . The planned $\varepsilon$ of Genesis was less than the delivered, $26.48 \%$.

Also completed in 2014, Mojave has delivered an annual $\varepsilon$ of $28.53 \%$ in $2016,27.12 \%$ in $2017,27.12 \%$ in 2018 , and $23.42 \%$ in 2019. The planned $\varepsilon$ of Mojave was about the delivery of the first year, $28.17 \%$. The performance of Mojave is now deteriorating.

Completed in 2013, Solana has delivered $\varepsilon$ of $29.37 \%$ in 2016 , $33.08 \%$ in $2017,35.43 \%$ in 2018 and $36.04 \%$ in 2019 . The planned $\varepsilon$ of Solana was better than the delivered, $43.11 \%$.

Completed in 2014, the $\varepsilon$ of Ivanpah, are marginally above $20 \%$ despite the considerable boost by natural gas combustion $19.78 \%$ in $2015,21.35 \%$ in $2016,21.75 \%$ in $2017,24.11 \%$ in 2018 , and $23.31 \%$ in 2019 . The planned $\varepsilon$ of Ivanpah was also much better than the delivered, $32.68 \%$, with negligible combustion of natural gas.

While the performance of Genesis is stable, and the performance of Mojave is deteriorating after only a few years, the performance of Solana is further improving even if minimally over the last 12 months.

Also, CSP PT installations completed in the 1980s and still operational, such as 7 of the 9 Solar Energy Generating Systems (SEGS) plants, work better than Crescent Dunes and Ivanpah.

At about $80 \mathrm{MW}$ each, the complex was producing $354 \mathrm{MW}$ of total power. SEGS IX has delivered a 2019 annual average $\varepsilon$ of $19.99 \%$, but with only a small contribution by natural gas combustion.

The data of electricity production and natural gas combustion used is provided by a reliable source, the United States Energy Information Administration (EIA), and it is in the public domain (EIA, 2019).

Figure 3 presents a comparison of the monthly $\varepsilon$ that a CSP with TES should deliver to achieve an annual average $\varepsilon$ of $51.89 \%$ as expected for Crescent Dunes, plus the actual $\mathcal{E}$ of Crescent Dunes, Genesis, Mojave, Solana, ISEGS, and SEGS IX over the last four years and during the year 2018.

The figure also presents the data of the SEGS IX plant since 2001 (this is the year the EIA statistic starts, but this plant is operational since 1990) showing the relatively stable production of this design. Since 2001, this plant has operated with an annual $\varepsilon$ maximum of $33.11 \%$, a minimum of $19.70 \%$, and an average of $24.61 \%$, with minimum support from the combustion of natural gas.

When there is a boost by natural gas combustion, the EIA differentiates between the sun and natural gas heat supply. As discussed in Boretti (2018a, 2018b), this attribution is incorrect for two reasons. First, natural gas would be better used in a 

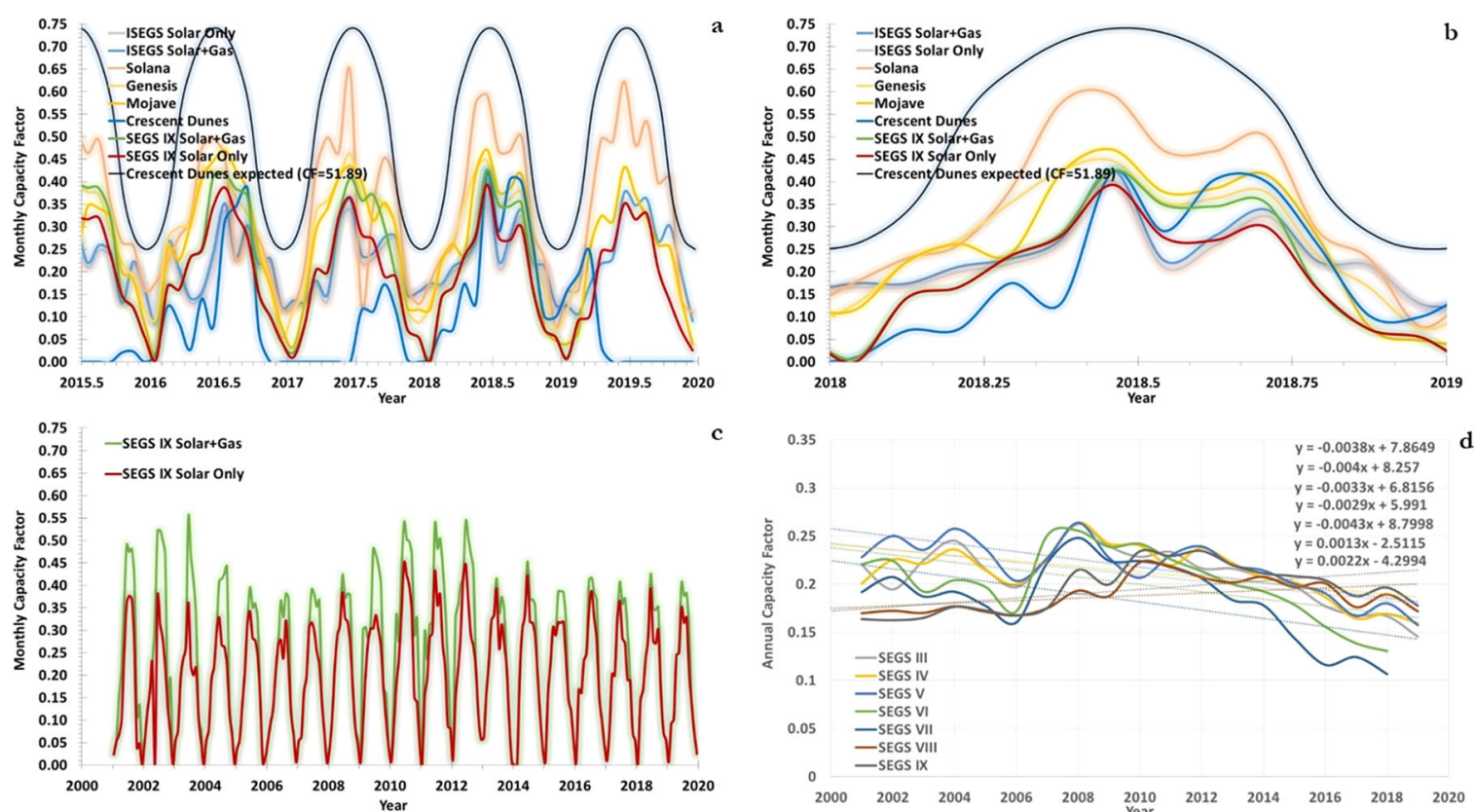

Fig. 3 Technical performances of existing CSP PT and ST plants with and without TES. $\mathbf{a}, \mathbf{b}$ The monthly $\varepsilon$ following seasonal irradiance variability of a CSP plant with molten salt TES delivering the annual average $\varepsilon$ of $51.89 \%$ expected for Crescent Dunes, and the actual $\varepsilon$ of the plants of Crescent Dunes CSP ST with $10 \mathrm{~h}$ molten salt TES, Genesis and Mojave CSP PT without any TES, Solana CSP PT with $6 \mathrm{~h}$ molten salt TES, ISEGS CSP PT without any TES but boosted by natural gas combustion, and SEGS IX, CSP PT without any TES but boosted by natural gas combustion over the last 3 years and the year 2018. The actual production data is from EIA (2019). c The data of the monthly $\varepsilon$ of the plant SEGS IX since 2001. 2001 is the year the EIA statistics start, but this plant has been operational since 1990. This image shows the stable solar production of this design. $\mathbf{d}$ The data of SEGS III to SEGS IX since 2001 for the solar production depurated of the natural gas boost as proposed by the EIA.

combined cycle gas turbine plant at twice the thermal efficiency of the power cycle. Second, without this boost, the solar-only plant is not able to deliver what is indicated as solar only.

The Figure also shows the data of the seven plants SEGS III to SEGS IX since 2001 for the solar production depurated of the natural gas boost as it is proposed by the EIA.

Worth of consideration, the life span of 30 years, which is above the 25 years typically optimistically used in the PPA for solar PV and wind, plus the relative stability of the sun output. A minimal decrement in the SEGS facilities $\varepsilon$ sun only is an artifact of reducing the natural gas boost in recent years, improperly accounted for in the EIA statistic.

For what concerns ISEGS and SEGS IX, the total electricity production is obtained by also burning natural gas. The boost by natural gas combustion is limited for SEGS IX and extreme for ISEGS.

According to the predictions of the 2012 report by (IRENA, 2012), Table 1, CSP ST plants with molten-salt TES should have had a cost between 2010 US\$ 6300 and 2010 US\$10,500/kW of installed power (capacity), with TES between 6 and $15 \mathrm{~h}$, and achieve $\varepsilon$ from 40 to $80 \%$, for electricity generation costs of about $2010 \mathrm{US} \$ / \mathrm{kWh} 0.17$ to 0.29 . By considering the inflation, this translates a cost between 2019 US $\$ / \mathrm{kW} 7371$ and 12,285, for electricity generation costs of about 2019 US\$/kWh 0.20 to 0.34 .

The National Renewable Energy Laboratory Annual Technology Baseline (ATB) 2018 and 2019 (NREL, 2018, 2019) also say that the present CSP technology is ST with molten-salt TES by a two-tank system. In their ATB, CSP plants with $10 \mathrm{~h}$ of TES are illustrated. This CSP ST with $10 \mathrm{~h}$ TES is the design featured by the Crescent Dunes plant, which they say is representative of most new molten-salt TES CSP ST projects.

The fact that the only plant of this kind has been working very badly and has been already shut down after only 4 years of life has not impacted the NREL ATB of the last few years. PT is ignored.
Table 1 CSP costs and performances in 2011 according to IRENA (2012).

\begin{tabular}{|c|c|c|c|}
\hline & $\begin{array}{l}\text { Installed cost ( } 2010 \\
\text { US } \$ / k W)\end{array}$ & $E(\%)$ & $\begin{array}{l}\text { Installed cost (2019 } \\
\text { US\$/kW) }\end{array}$ \\
\hline \multicolumn{4}{|c|}{ Parabolic trough $(\mathrm{PT})$} \\
\hline No storage & 4600 & 20 to 25 & 5382 \\
\hline $6 \mathrm{~h}$ of storage & 7100 to 9800 & 40 to 53 & 8307 to 11,466 \\
\hline \multicolumn{4}{|c|}{ Solar tower (ST) } \\
\hline $\begin{array}{l}6 \text { to } 7.5 \mathrm{~h} \text { of } \\
\text { storage }\end{array}$ & 6300 to 7500 & 40 to 45 & 7371 to 8775 \\
\hline $\begin{array}{l}12 \text { to } 15 \mathrm{~h} \text { of } \\
\text { storage }\end{array}$ & 9000 to 10,500 & 65 to 80 & 10,530 to 12,285 \\
\hline
\end{tabular}

Figure 4 presents the NREL Annual Technology Baseline (ATB) for CSP of 2018 and 2019. In (a) is the CAPEX (CAPital EXpenditures) in 2016 US $\$ / \mathrm{kW}$ of power installed, in (b) the $\varepsilon$, in (c) the O\&M cost per year and $\mathrm{kW}$ of power, and finally in (d) is the levelized cost of electricity (LCOE) of the 2018 ATB. In (e), (f), (g) and (h) are the revised figures of the 2019 ATB.

In the $2018 \mathrm{ATB}$, The CAPEX graph shows $8000 \mathrm{US} \$ \mathrm{~kW}$ as the 2016 value, and it suggests a rapid reduction of the CAPEX up to the time of the ATB and behind. Crescent Dunes, the only member of the population for this specific technology, had in 2015 a larger cost of 8863 US $\$ / \mathrm{kW}$. There were also added costs needed to put the plant back in operation after the failure of the molten-salt TES system also known at the time of the ATB, similarly ignored. A design such as Crescent Dunes does not have a CAPEX of 6600 US $\$ / \mathrm{kW}$ in 2021.

The $\varepsilon$ graph differentiates between fair, good, and excellent resources. A fair resource is Abilene, TX, $5.59 \mathrm{kWh} / \mathrm{m}^{2} /$ day. 

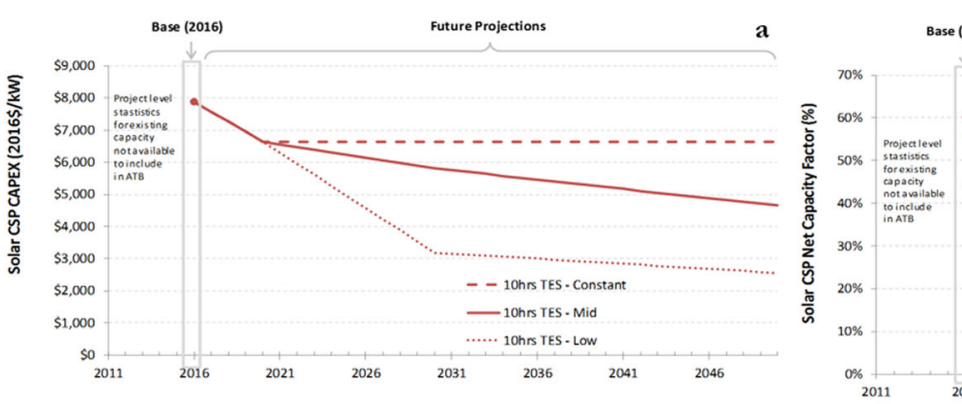

ase (2016)

Future Projections
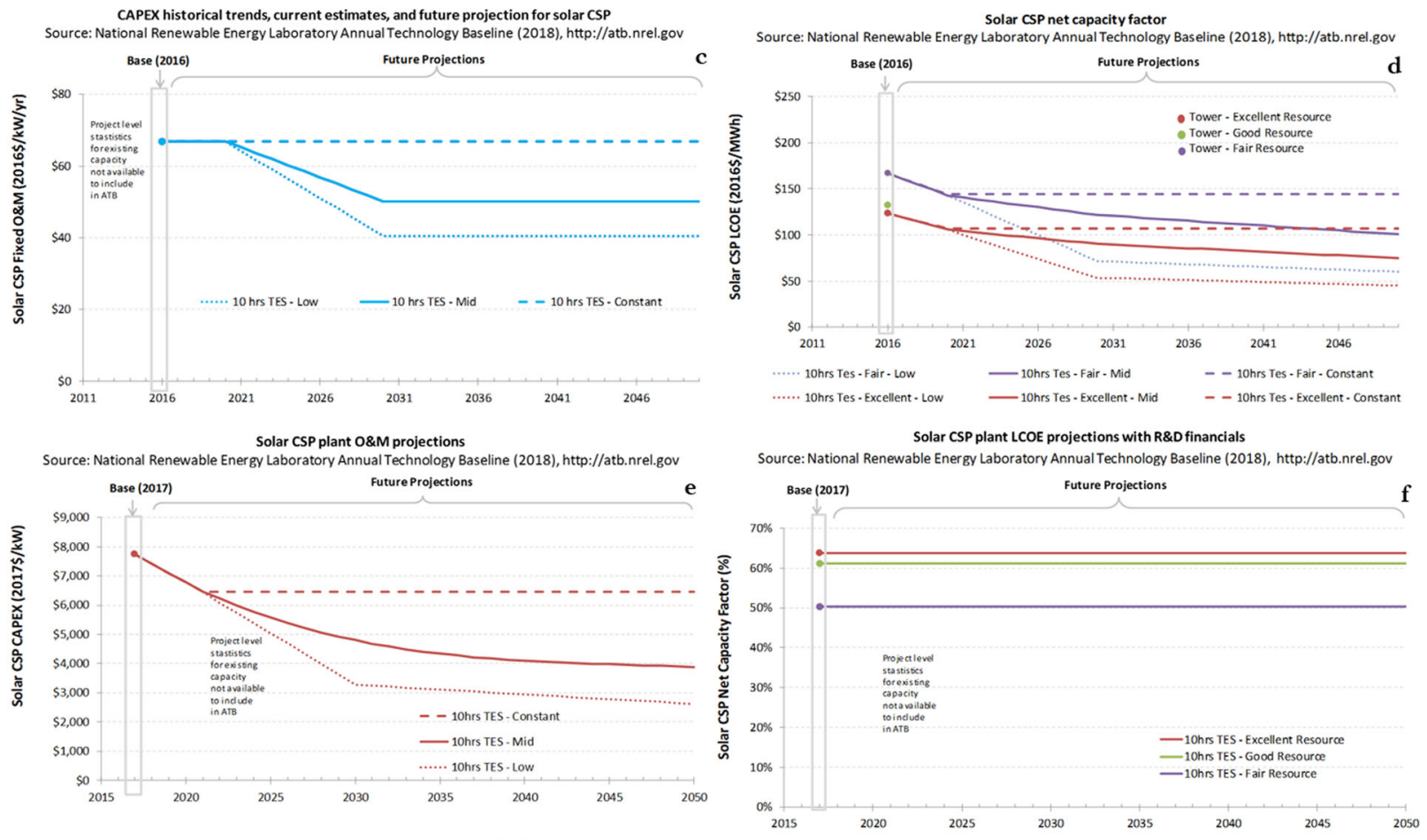

CAPEX historical trends, current estimates, and future projection for solar CSP
Source: National Renewable Energy Laboratory Annual Technology Baseline (2019), http://atb.nrel.gov
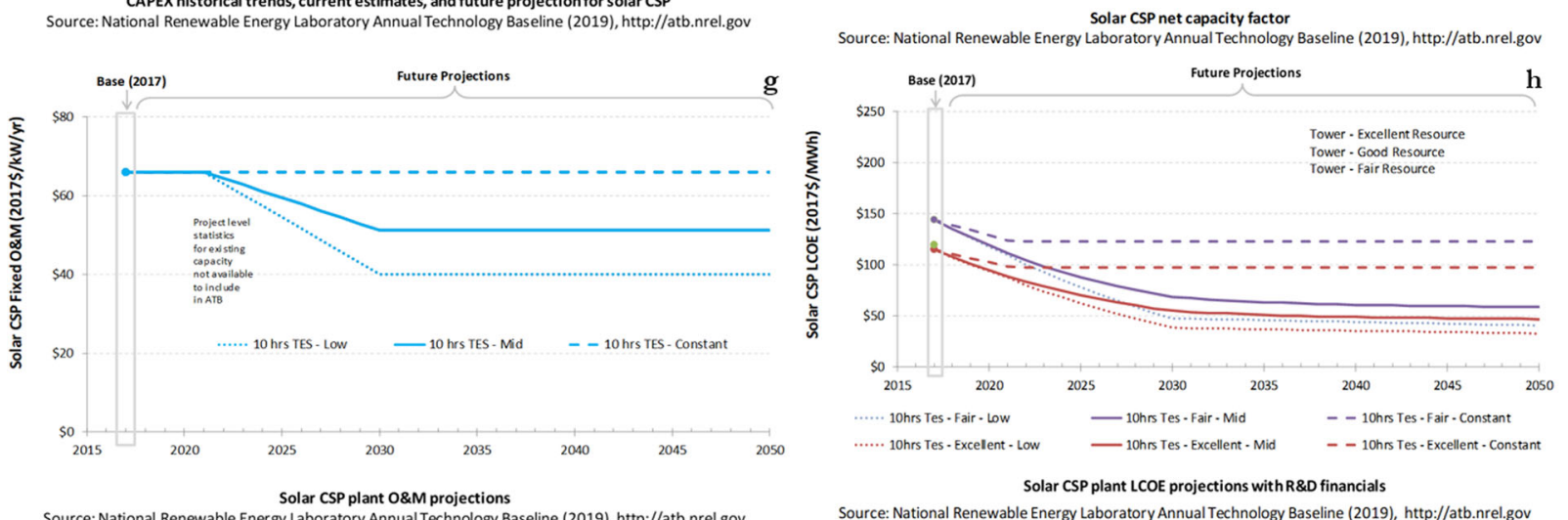

Fig. 4 Techno-economic performances of future CSP ST plants with TES. a-d The version 2018 of the NREL Annual Technology Baseline data for CSP, e-h the version 2019. a The CAPEX (CAPital EXpenditures) in 2016 US $\$$ per $\mathrm{kW}$ of power installed. b The net capacity factor $\varepsilon$. c The O\&M costs. d The Levelized costs of electricity. Images reproduced after NREL (2018). e-h The same projections of techno-economic parameters in version 2019. Images reproduced after NREL (2019). Credit DOE/NREL.

Here, according to NREL, the $\varepsilon$ was $42 \%$ in 2016. A good resource is Las Vegas, NV, $7.1 \mathrm{kWh} / \mathrm{m}^{2} /$ day. Here, according to NREL, the $\varepsilon$ was $56 \%$ in 2016 . Finally, an excellent resource is Daggett, CA, $7.46 \mathrm{kWh} / \mathrm{m}^{2} /$ day. Here, according to NREL, the $\varepsilon$ was $59 \%$ in 2016 . Crescent Dunes, the only member of the population for this specific technology, in a site of excellent resource, Tonopah, NV, $7.36 \mathrm{kWh} / \mathrm{m}^{2} /$ day, commissioned in
2015, had in 2015 an $\varepsilon$ of $0.37 \%$ in the three months it was run, then an $\varepsilon$ of $13.20 \%$ in 2016. The $\varepsilon$ of 2017 and 2018 has been $4.33 \%$ and $20.29 \%$.

Regarding the Levelized cost of electricity, starting from an underrated present, the ATB then proposes an optimistic evolution, based on expectations of future technological improvements and cost reductions. Crescent Dunes was not delivering electricity 
at $120 \mathrm{US} \$ / \mathrm{MWh}$ in 2016, and unlikely about the same design will allow electricity production at $100 \mathrm{US} \$ / \mathrm{MWh}$ in 2021.

Moving from the 2018 ATB to the 2019 ATB, the only additional real-world information that could have motivated revised data is the further troublesome operation of Crescent Dunes. What we learn from Fig. 4 is that the CAPEX of 2017 is slightly less than the CAPEX of 2016, but the new CAPEX of 2050 is otherwise much less, 3950 US\$ vs. 4800 US\$ (mild trend). However, $\varepsilon$ has dramatically increased from 60 to $65 \%$ (excellent resources). The LCOE moves down accordingly.

Based on a subjective interpretation of the signature of the PPA of Aurora, but not the cancellation of this project the same as the other projects by the same developer, these predictions have been made even more unrealistic. (Murphy et al., 2019) assumes a present cost of only $61 \mathrm{US} \$ / \mathrm{MWh}$ and proposes a cost even lower to $50 \mathrm{US} \$ / \mathrm{MWh}$ by 2030 .

\section{Discussion}

In power generation, for other technologies, there are many power plants built and operated featuring the specific technology. Thus, cost and electricity production can be forecasted based on real-world information such as the construction cost, the costs to operate the plant, and the electricity production expected. If the technology is evolving, a reliable estimation of what can be expected soon in absence of a breakthrough may then be obtained by using one forecasting method. None will produce definitive answers, as nobody can see the future. Commonly used are moving averages, Exponential Smoothing (ETS), linear regression, parabolic regression. This procedure cannot apply for CSP, in the specific ST technology with TES.

Reality has been far from the predictions by NREL (2018) or NREL (2019), as shown in Boretti (2018a, 2018b), and Boretti et al. (2018), with much larger costs per unit of energy produced, because of the much smaller $\varepsilon$, and the much larger construction costs, of the ST plants, that have been so far inferior to the PT design.

High-frequency generation data every minute or less are unavailable for CSP. This data is, however, essential to understanding if the models are really helpful. There is no data on electricity production from CSP with better than monthly resolution, which is definitively not enough to appreciate the variability, or also to validate models.

Without accounting for the variability of the electricity supply, CSP makes no sense, as solar PV and wind are much cheaper. As a stable grid needs a stable supply matching the demand instantaneously, the key turn point in renewable energy is to quantify and price variability. A kWh of electricity available only during daylight time, or when the wind blows, has a different value from a dispatchable $\mathrm{kWh}$ of electricity. Thus, a variability parameter must be added the sooner the better in the technology forecasting.

Data of resource, weather, as well as of plant components as well as plant output, should be collected simultaneously over a full year with high-frequency sampling to permit a proper validation of the models and their components. Dramatic differences between expected and delivered performances are an indication that the design is made by assuming the operation of components and systems that are excessively optimistic. This poses the issue of substandard components, for example, a heat exchanger not providing the expected reliability, under transient loads, and failing, or heliostats losing track.

The largest CSP ST with monthly electricity production data and construction cost information is the previously mentioned Ivanpah completed in January 2014. The plant has performed so far well below the expectations, despite burning a much larger than planned amount of natural gas to boost combustion. There have been so far several failures. Performance degradation is unknown. The costs for repairs and the costs of using natural gas are unclear. The cost per $\mathrm{kWh}$ is difficult to be assessed. Construction costs were 2.2 billion US\$ in 2014. The life span of the much simpler and more reliable CSP PT is 30 years. The life span of the more complex ST is not expected to be that long, especially without major maintenance works. From January 2014 to September 2019 included (69 months) Ivanpah has produced $3,899,050 \mathrm{MWh}$ of electricity. Over the same time frame, Ivanpah has also burned 5,790,918 million Btu of natural gas, with however data for 7 months of the 69 missing not available or not reported. If we take optimistically a life span of 25 years or 300 months, Ivanpah will deliver a cost per kWh of roughly 0.13 US\$/kWh neglecting the repairs and the cost of the natural gas. Considering the cost of natural gas is presently very low, natural gas combustion does not increase too much the cost of electricity. The about $2.8 \cdot 10^{7}$ million Btu of natural gas that is expected to be burned by Ivanpah translates into a $\mathrm{CO}_{2}$ emission of $1.49 \cdot 10^{9} \mathrm{~kg}$ (1 million Btu of natural gas has an associated emission of $53.07 \mathrm{~kg}$ of $\mathrm{CO}_{2}$ ).

The only other CSP ST with monthly electricity production data and construction cost information is the previously mentioned Crescent Dunes completed in October 2015. Up to November 2019, Crescent Dunes, which had a cost of 0.975 billion US\$ in 2015, has only produced 418,849 MWh of electricity over 50 months of irregular production, with many interruptions, with the last electricity produced in April 2019. This is only $2,513,094 \mathrm{MWh}$ over 25 years or $0.39 \$ / \mathrm{kWh}$. As reported by Deign (2020), the developer, Solar Reserve appears to have ceased operations.

With only these two CSP ST power plants in the database of costs and electricity production above $100 \mathrm{MW}$ of installed capacity, it is certainly impossible to conclude what this specific technology can deliver in terms of dispatchable solar electricity and at which costs.

Having a statistically significant population of facilities, for what concerns the cost, if $\mathrm{CAPEX}_{i, j}$ is the cost per unit nominal power, $P_{i, j}$ is this nominal power, and $\varepsilon_{i, j}$ is the annual capacity factor of the facility $i$, completed in the year $j$, then the average CAPEX $_{\mathrm{j}}$ over all the $n$ facilities completed in the year $j$ is:

$$
\operatorname{CAPEX}_{j}=\frac{\sum_{i=1}^{n} \frac{\operatorname{CAPEX}_{i, j}}{\varepsilon_{i, j}} \cdot \varepsilon_{i, j} \cdot P_{i, j}}{\sum_{i=1}^{n} \varepsilon_{i, j} \cdot P_{i, j}}=\frac{\sum_{i=1}^{n} \operatorname{CAPEX}_{i, j} \cdot P_{i, j}}{\sum_{i=1}^{n} \varepsilon_{i, j} \cdot P_{i, j}}
$$

This number should be then corrected for the energy storage allowance.

Similarly, the $\mathrm{LCOE}_{j}$ is obtained as the generation averaged of the $\operatorname{LCOE}_{i, j}$.

$$
\operatorname{LCOE}_{j}=\frac{\sum_{i=1}^{n} \frac{\operatorname{LCOE}_{i, j}}{\varepsilon_{i, j}} \cdot \varepsilon_{i, j} \cdot P_{i, j}}{\sum_{i=1}^{n} \varepsilon_{i, j} \cdot P_{i, j}}=\frac{\sum_{i=1}^{n} \operatorname{LCOE}_{i, j} \cdot P_{i, j}}{\sum_{i=1}^{n} \varepsilon_{i, j} \cdot P_{i, j}}
$$

Also looking at the generation average values for what concerns performance, at least two parameters should be considered. One parameter is the annual average $\varepsilon_{j}$, and one additional parameter introduced to represent the variability about the annual average value is the standard deviation of the capacity factor $\delta_{j}$.

A more appropriate LCOE should be based not only on CAPEX, $\varepsilon$, and the O\&M costs, but also include the grid energy storage allowance, which depends on $\varepsilon$ and $\delta$ (Boretti, 2019b, 2019c; Boretti and Castelletto, 2020). 
The $\varepsilon$ of the different facilities in the statistical sample considered for the year $\mathrm{j}$ are also weighed on the electricity generated:

$$
\begin{gathered}
\varepsilon_{j}=\frac{\sum_{i=1}^{n} \frac{\varepsilon_{i, j}}{\varepsilon_{i, j}} \cdot \varepsilon_{i, j} \cdot P_{i, j}}{\sum_{i=1}^{n} \varepsilon_{i, j} \cdot P_{i, j}}=\frac{\sum_{i=1}^{n} \varepsilon_{i, j} \cdot P_{i, j}}{\sum_{i=1}^{n} \varepsilon_{i, j} \cdot P_{i, j}} \\
\delta_{j}=\frac{\sum_{i=1}^{n} \frac{\varepsilon_{i, j}}{\varepsilon_{i, j}} \cdot \varepsilon_{i, j} \cdot P_{i, j}}{\sum_{i=1}^{n} \varepsilon_{i, j} \cdot P_{i, j}}=\frac{\sum_{i=1}^{n} \varepsilon_{i, j} \cdot P_{i, j}}{\sum_{i=1}^{n} \varepsilon_{i, j} \cdot P_{i, j}}
\end{gathered}
$$

Finally, forecasting techniques should be applied to the $\mathrm{CAPEX}_{j}, \operatorname{LCOE}_{j} \varepsilon_{j}$ or $\delta_{\mathrm{j}}, j=1, \ldots, m$, where $m$ is the time level, to infer the time trends.

Regarding CSP PT, even at $8720 \mathrm{US} \$ / \mathrm{kW}$, an $\varepsilon$ of $36 \%$, O\&M costs of $66 \mathrm{US} \$ / \mathrm{kW} /$ year, a plant such as Solana may permit an LCOE of $11.3 \mathrm{c}$ US $\$ / \mathrm{kWh}$ working 30 years. Similarly, at 5360 US $\$ / \mathrm{kW}$, an $\varepsilon$ of $28 \%$, O\&M costs of $50 \mathrm{US} \$ / \mathrm{kW} /$ year (O\&M with TES are significantly larger) a plant such as Genesis may permit an LCOE of 9.3 c US $\$ / \mathrm{kWh}$ working 30 years. By further refining this design and mass-producing the components, this cost can be dramatically reduced, possibly to get much closer to the $6 \mathrm{c}$ US $\$ / \mathrm{kWh}$ incorrectly attributed to the ST with TES technology of Crescent Dunes.

CSP PT works much better than CSP ST. With no TES, PT work even better than the modeled expectations. With TES, they work slightly less than the modeled expectations.

Technology forecasting for CSP should also include PT, not only ST.

As an added remark, the present LCOE does not account for the variability of the power of electricity generation vs. the registered capacity.

In a system of wholesale spot prices, failure to deliver below $80 \%$ of the registered capacity has huge consequences. These consequences are presently voided for wind and solar power generation facilities, but cannot be avoided forever. With spot prices, up to $14 \mathrm{AU} \$ / \mathrm{kWh}$ vs. averages of $10 \mathrm{c} \mathrm{AU} \$ / \mathrm{kWh}$, and harsh penalties for failing to provide the promised outputs for other generations, is not reasonable to discuss LCOE of unpredictable electricity.

Every facility producing unpredictable electricity needs a backup predictable facility, or dedicated energy storage to be accepted in the grid, where demand and supply are always balanced. While every facility does not have to be balanced individually, sooner or later the cost of balancing the grid will have to be shared among the different facilities supplying intermittent electricity, and the cost will have to be proportional to the value of the mean $\varepsilon$, as well as to a parameter such as the $\delta$ expressing the variability.

There have been expectations of unrealistic LCOE for specific CSP technology, ST with TES, to compete price-wise with wind and solar PV, without accounting for dispatchability. CSP is not competitive with solar PV or wind without factoring in dispatchability. CSP is however a key component of renewable energy-only grid, where not controllable electricity from wind and solar PV must be integrated with continuous or dispatchable electricity from CSP, hydro, or enhanced geothermal systems (EGS) plus the affordable amount of batteries and pumped hydro to have supply matching demand (Boretti, 2021a).

The claim of a present cost of CSP ST with TES of US\$ 0.061 per $\mathrm{kWh}$, further projected to reach US\$ 0.05 per kWh by 2030 , are speculations not based on any real-world data that have worsened rather than improved the perspectives of CSP ST with TES. It will take years to recover the sector from the bad reputation gathered from the Crescent Dunes and Aurora experiences.

The failure of Crescent Dunes is only the result of the attempt to compete price-wise with wind and solar PV without accounting for dispatchability. Regarding the Gemasolar CSP ST with TES design, Crescent Dunes had a smaller size of the solar field of heliostats per MW of turbine power $\left(10,911 \mathrm{~m}^{2}\right.$ vs. $15,900 \mathrm{~m}^{2}$ ). Accounting for the higher solar resource of Crescent Dunes, this is still significantly less (solar input per MW of power $28,915,162 \mathrm{kWh} / \mathrm{yr}$. vs. 33,390,000 kWh/yr.). Thermal storage was also less, 10 vs. $15 \mathrm{~h}$.

By exploring, in the default model of SAM (NREL, 2020) for CSP ST with TES, that includes the latest costs of performances by NREL, the opportunity of adopting a larger TES as well as a larger solar field vs. the suggested optimum, for a $110 \mathrm{MW}$ plant in the specific location of NEOM City, it is found (Boretti and Castelletto, 2021a) that:

Increasing the TES from 10 to $16 \mathrm{~h} \mathrm{LCOE,} \mathrm{mean} \varepsilon$ and $\delta$ all improve;

By increasing the size of the solar field from less than 10,000 $12.2 \times 12.2 \mathrm{~m}^{2}$ heliostats to $13,000-13,500$ heliostats LCOE, mean $\varepsilon$ and $\delta$ all improve;

By further increasing the size of the solar field with heliostats above 13,500 , mean $\varepsilon$ and $\delta$ all improve, but LCOE increases. By increasing the number of heliostats from 13,500 to 18,500 permits $\varepsilon \sim 95 \%$ at an LCOE of less than $8 \mathrm{c} / \mathrm{kWh}$ for continuous electricity supply in NEOM city.

Also accepting 20\% higher costs, the solution would be very competitive with solar PV and batteries, of expected life and performance much worse in the Kingdom of Saudi Arabia than elsewhere cause sand, dust, and high temperatures.

Apart from failures, regarding the modeling of CSP ST, there is the issue of the real operation of components differing from the design conditions. For example, heliostats lose tracking in time subjected to atmospheric load, and other components suffer from real-world operation performance differing from the operation assumed in the models. Especially in ST, the solar field collection is dramatically affected by the presence of clouds. Accurate models validated under realistic cloud coverage are still missing, even because real-world instantaneous data of electricity production and irradiance are missing. The effects of clouds make unreliable every prediction of CSP ST with molten-salt TES plants' performances. Thermal transients are particularly challenging in CSP ST with molten-salt TES.

The further progress of CSP will depend on the successful operation of the novel solar facilities such as Dubai One, featuring CSP parabolic trough with TES, CSP solar tower with TES, and $\mathrm{PV}$ in the different units. Only full transparency on the construction and maintenance costs, as well as of electricity production sampled with high frequency, plus the sharing of plant characteristics and high-frequency data of system and components operation, resource and other environmental variables for modeling, may bring back confidence in the CSP technology.

\section{Conclusions}

The work has reported the CSP plants that have been developed or proposed, locally and overseas, highlighting the reasons for the poor uptake of this technology, especially in Australia. CSP is more sophisticated, less widespread, and therefore more expensive and less reliable than wind and solar PV. During the early growth phase of renewable energy, when the interest is to quickly build up capacity, wind and solar PV have huge advantages vs. CSP having a cost per unit installed power that is much less. The attempt to compete price-wise with wind and solar PV is what has produced substandard developments that have undermined the reputation of CSP technology. It is in the current growth phase of renewable energy, where the aim is to make a grid renewable energy only without any supply from combustion fuels, that the energy storage issue is coming out, and CSP is gaining 
new interest. Opposite to wind and solar PV power plants that may deliver power to the grid only phased with the contemporary, instantaneous, availability of the wind and solar resource, and thus necessitates of huge energy storage, which is economically very expensive, CSP plants have the advantage of dispatchability, i.e., production of electricity on demand, thanks to the much cheaper internal thermal energy storage. Further developed for higher temperatures, (Boretti and Castelletto, 2021b), CSP may have better efficiencies of the thermal cycle and reduced LCOE. While a CSP plant cannot have a levelised cost of generic electricity lower than a PV solar plant, it may have a much lower cost of similarly dispatchable electricity from a PV solar plant plus BES. Aiming at a renewable energy-only grid, CSP is therefore expected to grow even more than solar PV and wind, in a grid managed by artificial intelligence (Boretti, 2021a) that is however built on the supply of power of different characteristics from wind, solar PV, and CSP, stabilized by BES and PHES, and production of green hydrogen - the hydrogen economy is complementary and synergetic to the electric economy (Boretti, 2021b) - with further quality contributors hydroelectric, biomass and possibly enhanced geothermal energy (Boretti, 2021c) and nuclear. While renewable hydrogen production is expected to progress in the current phase as green hydrogen, from excess wind and solar photovoltaic electricity and electrolysis, it must be mentioned that higher temperature concentrated solar energy and thermal energy storage may be used to run a thermochemical hydrogen production plant rather than a hightemperature power cycle with clear synergies between electricity production and production of hydrogen (Boretti, 2021d, e). CSP ST with TES is the most promising renewable energy technology permitting dispatchability. It must be competitive when dispatchability is factored in, not without. Until the pricing will include dispatchability, it will suffer from the competition of the much cheaper wind and solar PV, which, however, are not dispatchable without the unaffordable batteries. Fully dispatchable solar electricity from CSP ST with TES is achievable in Australia for $8-10 \mathrm{c} / \mathrm{kWh}$, well below every alternative.

\section{Data availability}

No new data were generated in this work. The data used across the work are available at the listed references.

Received: 19 January 2021; Accepted: 28 November 2021; Published online: 15 December 2021

\section{References}

ABC News (2017) Solar thermal power plant announced for Port Augusta 'biggest of its kind in the world'. http://mobile.abc.net.au/news/2017-08-14/solarthermal-power-plant-announcement-for-port-augusta/8804628

ABC News (2019) Port Augusta solar thermal power plant scrapped after failing to secure finance. www.google.com/amp/amp.abc.net.au/article/10973948

Aneroid Energy (2019) Energy data from the Australian Energy Market Operator. http://anero.id/energy/

Australian Government Department of the Environment and Energy (2019) Australian Energy Statistics, Table Of Electricity generation by fuel type 2017-18 and 2018. www.energy.gov.au/publications/australian-energystatistics-table-o-electricity-generation-fuel-type-2017-18-and-2018

Baig M, Surovtseva D, Halawa E (2015) The potential of concentrated solar power for remote mine sites in the Northern Territory, Australia. J Sol Energy 2015:617356.

Boerema N, Morrison G, Taylor R, Rosengarten G (2013) High temperature solar thermal central-receiver billboard design. Sol Energy 97:356-368

Boretti A (2018a) Concentrated solar power plants capacity factors: a review, nonlinear approaches, in engineering applications energy: vibrations, and modern applications, Liming Dai, Eds., Reza N. Jazar. Springer, New York, NY
Boretti A (2018b) Cost and production of solar thermal and solar photovoltaics power plants in the United States. Renew Energy Focus 26:93-99

Boretti A, Castelletto S, Al-Zubaidy S (2018) Concentrating solar power tower technology: present status and outlook. Nonlinear Engineering 8(2). https:// doi.org/10.1515/nleng-2017-0171

Boretti A (2019a) Realistic expectation of electricity production from current design concentrated solar power solar tower with thermal energy storage. Energy Storage https://doi.org/10.1002/est2.57

Boretti A (2019b) Energy storage requirements to address wind energy variability. Energy Storage 1(5):e77. https://doi.org/10.1002/est2.77

Boretti A (2019c) Energy storage needs for an Australian National Electricity Market grid without combustion fuels. Energy Storage. https://doi.org/10.1002/est2.92

Boretti A, Castelletto S (2020) Cost of wind energy generation should include energy storage allowance. Sci Rep 10(1):1-13

Boretti A, Castelletto S (2021a) Concentrated Solar Power Solar Tower with Oversized Solar Field and Molten Salt Thermal Energy Storage working at an annual average capacity factor of 95\% in NEOM City. Energy Technol 9(4). https://doi.org/10.1002/ente.202001097

Boretti A, Castelletto S (2021b) High-temperature molten-salt thermal energy storage and advanced-Ultra-supercritical power cycles. J Energy Storage 42:103143

Boretti A (2021a) Integration of solar thermal and photovoltaic, wind, and battery energy storage through AI in NEOM city. Energy AI 3:100038

Boretti A (2021b) The hydrogen economy is complementary and synergetic to the electric economy. Int J Hydrog Energy 46(78):38959-38963

Boretti A (2021c) Dispatchable renewable energy from CSP and CSP+EGS in the Kingdom of Saudi Arabia, 11th International Conference on Renewable and Clean Energy 26-28 February. Shiga, Japan. IOP Conf. Ser.: Earth Environ. Sci. 813:012003. https://doi.org/10.1088/1755-1315/813/1/012003

Boretti A (2021d) A perspective on the production of hydrogen from solar-driven thermal decomposition of methane. Int J Hydrog Energy 46(69):34509-34514

Boretti A (2021e) White is the color of hydrogen from concentrated solar energy and thermochemical water splitting cycles. Int J Hydrog Energy 46(39):20790-20791

Clifton J, Boruff BJ (2010) Assessing the potential for concentrated solar power development in rural Australia. Energy Policy 38(9):5272-5280

Dawson L, Schlyter P (2012) Less is more: Strategic scale site suitability for concentrated solar thermal power in Western Australia. Energy Policy 47:91-101

Deign J (2020) America's concentrated solar power companies have all but disappeared. www.greentechmedia.com/articles/read/americas-concentratedsolar-power-companies-have-all-but-disappeared

Energy Information Administration (US DOE) (2019) ELECTRICITY DATA BROWSER. www.eia.gov/beta/electricity/data/browser/

Feldman D, Margolis R (2018) Q1/Q2 2018 Solar Industry Update. National Renewable Energy Laboratory, Golden,CO, www.nrel.gov/docs/fy18osti/ 72036.pdf NREL/PR-6A20-72036

Ghadi MJ, Li L, Zhan J, Chen L, Huang Q, Li C (2019) A Review on the development of concentrated solar power and its Integration in coal-fired power plants. In 2019 IEEE Innovative Smart Grid Technologies-Asia (ISGT Asia). IEEE. pp. 1106-1111

Herrmann U, Kelly B, Price H (2004) Two-tank molten salt storage for parabolic trough solar power plants. Energy 29(5-6):883-893

International Renewable Energy Agency (2012) Concentrating Solar Power. www.irena.org/documentdownloads/publications/ re_technologies_cost_analysis-csp.pdf

Kuravi S, Trahan J, Goswami DY, Rahman MM, Stefanakos EK (2013) Thermal energy storage technologies and systems for concentrating solar power plants. Prog Energy Combust Sci 39(4):285-319

Lilliestam J, Labordena M, Patt A, Pfenninger S (2017) Empirically observed learning rates for concentrating solar power and their responses to regime change. Nat Energy 2:17094

Lilliestam J, Pitz-Paal R (2018) Concentrating solar power for less than USD 0.07 per kWh: finally the breakthrough? Renew Energy Focus 26:17-21

Law EW, Prasad AA, Kay M, Taylor RA (2014) Direct normal irradiance forecasting and its application to concentrated solar thermal output forecasting-A review. Solar Energy 108:287-307

Law EW, Kay M, Taylor RA (2016) Calculating the financial value of a concentrated solar thermal plant operated using direct normal irradiance forecasts. Solar Energy 125:267-281

Middelhoff E, Madden B, Ximenes F, Carney C, Florin N (2022) Assessing electricity generation potential and identifying possible locations for siting hybrid concentrated solar biomass (HCSB) plants in New South Wales (NSW), Australia. Appl Energy 305:117942

Müller-Steinhagen H, Trieb F (2004) Concentrating solar power. A review of the technology. Ingenia Inform QR Acad Eng 18:43-50

Murphy C, Sun Y, Cole W, Maclaurin G, Turchi C, Mehos M (2019) The potential role of concentrating solar power within the context of DOE's 2030 Solar Cost Target. National Renewable Energy Laboratory. NREL/TP-6A20-71912, Golden, CO, http://www.nrel.gov/docs/fy19osti/71912.pdf 
Narimani A, Abeygunawardana A, Ledwich GF, Nourbakhsh G (2016) Value of concentrated solar power with thermal energy storage in the national electricity market of Australia. In 2016 Australasian Universities Power Engineering Conference (AUPEC) (pp. 1-5). IEEE

National Renewable Energy Laboratory (2018) Concentrating Solar Power Annual Technology Baseline 2018. http://atb.nrel.gov/electricity/2018/index.html?t=sc

National Renewable Energy Laboratory (2019) Concentrating Solar Power Annual Technology Baseline 2019. http://atb.nrel.gov/electricity/2019/index.html?t=sc

National Renewable Energy Laboratory (2020) System advisor model (SAM). http://sam.nrel.gov/

Parkinson G (2013) Graph of the Day: Australian retail electricity prices in 2020. http://reneweconomy.com.au/graph-of-the-day-australian-retail-electricityprices-in-2020-2020/

Peterseim JH, Herr A, Miller S, White S, O'Connell DA (2014) Concentrating solar power/alternative fuel hybrid plants: Annual electricity potential and ideal areas in Australia. Energy 68:698-711

Pitz-Paal R (2017) Concentrating solar power: still small but learning fast. Nat Energy 2:17095

Rehman S, Al-Hadhrami LM, Alam MM (2015) Pumped hydro energy storage system: a technological review. Renew Sustain Energy Rev 44:586-598

reneweconomy.com.au (2018) World's biggest solar tower with storage starts commissioning. reneweconomy.com.au/worlds-biggest-solar-tower-withstorage-starts-commissioning-77818/

Sills B, Daya A (2010) Dust blocking sun rays at solar plant in abu dhabi, masdar official says. www.bloomberg.com/news/articles/2010-10-27/dust-blockingsun-s-rays-at-solar-plant-in-uae-masdar-official-says

smh.com.au (2018) South Australia planning to build the world's largest thermal solar plant. www.google.com/amp/s/amp.smh.com.au/business/companies/ south-australia-aim-for-another-renewable-world-first-20180110p4yyd7.html

Yang Z, Garimella SV (2010) Thermal analysis of solar thermal energy storage in a molten-salt thermocline. Solar Energy 84(6):974-985

\section{Acknowledgements}

The authors want to thank Andrew Miskelly for permission to reuse the images of his website in the manuscript.

\section{Author contributions}

$\mathrm{AB}$ defined the method. $\mathrm{AB}$ and $\mathrm{SC}$ both downloaded and analyzed data, and discussed the results. $\mathrm{AB}$ wrote the first draft of the manuscript. Both authors participated in the further revisions of the manuscript.

\section{Competing interests}

The authors declare no competing interests.

\section{Ethical approval}

Ethical approval statement not needed as the research did not involve human participants. The research was performed following relevant guidelines/regulations not requiring ethical approval.

\section{Informed consent}

Informed consent not needed as the research did not involve human participants. This article does not report of any studies with human participants performed by any of the authors.

\section{Additional information}

Supplementary information The online version contains supplementary material available at https://doi.org/10.1057/s41599-021-01005-3.

Correspondence and requests for materials should be addressed to Alberto Boretti.

Reprints and permission information is available at http://www.nature.com/reprints

Publisher's note Springer Nature remains neutral with regard to jurisdictional claims in published maps and institutional affiliations.

\begin{abstract}
(c) (1)
Open Access This article is licensed under a Creative Commons Attribution 4.0 International License, which permits use, sharing, adaptation, distribution and reproduction in any medium or format, as long as you give appropriate credit to the original author(s) and the source, provide a link to the Creative Commons license, and indicate if changes were made. The images or other third party material in this article are included in the article's Creative Commons license, unless indicated otherwise in a credit line to the material. If material is not included in the article's Creative Commons license and your intended use is not permitted by statutory regulation or exceeds the permitted use, you will need to obtain permission directly from the copyright holder. To view a copy of this license, visit http://creativecommons.org/ licenses/by/4.0/
\end{abstract}

(C) The Author(s) 2021 